\title{
BMJ Open Implementation of the WHO's collaborative framework for the management of tuberculosis and diabetes: a scoping review
}

Rita Suhuyini Salifu (D) , ${ }^{1,2}$ Mbuzeleni Hlongwa (1) , , ${ }^{1,3}$ Khumbulani Hlongwana ${ }^{1}$

To cite: Salifu RS, Hlongwa M, Hlongwana K. Implementation of the WHO's collaborative framework for the management of tuberculosis and diabetes: a scoping review. BMJ Open 2021;11:e047342. doi:10.1136/ bmjopen-2020-047342

- Prepublication history and additional supplemental material for this paper are available online. To view these files, please visit the journal online (http://dx.doi.org/10.1136/ bmjopen-2020-047342).

Received 30 November 2020 Accepted 01 November 2021

Check for updates

(C) Author(s) (or their employer(s)) 2021. Re-use permitted under CC BY-NC. No commercial re-use. See rights and permissions. Published by BMJ.

${ }^{1}$ Discipline of Public Health Medicine, School of Nursing and Public Health, University of KwaZulu-Natal College of Health Sciences, Durban, KwaZulu-

Natal, South Africa

${ }^{2}$ Health and Development Solutions Network, Tamale, Ghana

${ }^{3}$ Burden of Disease Research Unit, South African Medical Research Council, Cape Town, South Africa

Correspondence to Rita Suhuyini Salifu; suhyini@gmail.com

\section{ABSTRACT}

Objective To map evidence on the implementation of the WHO's collaborative framework for the management of tuberculosis (TB) and diabetes mellitus (DM) comorbidity, globally.

Design Scoping review.

Methods Guided by Arksey and 0'Malley's scoping review framework, this review mapped literature on the global implementation of the framework for the management of TB and DM comorbidity, globally. An extensive literature search for peer-reviewed studies, theses, studies in the press and a list of references from the selected studies was conducted to source-eligible studies. PubMed, Google Scholar, Web of Science, Science Direct, the EBSCOhost platform (academic search complete, health source: nursing/academic edition, CINAHL with full text), Scopus and the WHO library were used to source the literature. We performed title screening of articles using keywords in the databases, after which two independent reviewers (RS and PV) screened abstracts and full articles. Studies from August 2011 to May 2021 were included in this review and the screening was guided by the inclusion and exclusion criteria. Findings were analysed using the thematic content analysis approach and results presented in the form of a narrative report. The Preferred Reporting Items for Systematic Reviews and Meta-Analysis extension was used as a checklist and for explaining the scoping review process.

Results This review found evidence of the WHO TB-DM collaborative framework's implementation in 35 countries across the globe. TB-DM comorbidity was identified in patients through bidirectional screening of both patients with TB and patients with DM in rural and urban settings. Conclusion Due to the paucity of evidence on mechanisms of collaboration, we recommend further research in other implementing countries to identify techniques used for diagnosis and integration of TB and DM services, in order to ensure that effective and joint management of TB-DM comorbidity in populations is achieved.

\section{INTRODUCTION}

Current tuberculosis (TB)-diabetes mellitus (DM) co-epidemic imposes strain on the strategies to control rising TB and DM prevalence across the globe. ${ }^{2}$ Healthcare systems are

\section{STRENGTHS AND LIMITATIONS OF THIS STUDY}

$\Rightarrow$ The search strategy was rigorous and covered an extensive range of databases to give a comprehensive review of the global implementation of the WHO collaborative framework.

$\Rightarrow$ All included studies underwent quality appraisal using an approved tool, namely: the Mixed Method Appraisal Tool.

$\Rightarrow$ This review only included articles published in English language and this may have excluded some relevant studies published in other languages. This review was guided by Arksey and O'Malley's framework, a widely used framework for conducting scoping reviews, which ensures a clear methodological and transparent process that can be replicated.

also being challenged to rethink diagnostic accuracy, co-management of the two diseases, and re-evaluation of the vertical nature of TB and DM management. ${ }^{3}$ The past decade has shown that the TB-DM co-epidemic has severe public health consequences, mainly because TB affects one-fourth of the global population. ${ }^{4}$

$\mathrm{DM}$ is one of the top four noncommunicable diseases causing mortality worldwide; and in the year 2019, approximately 1.5 million deaths were attributed to DM, globally. ${ }^{5}$ Globally, an estimated $15 \%$ of people with TB can be associated with DM. ${ }^{6}$ The 22 countries known to bear $80 \%$ of the global TB burden had TB infections due to $\mathrm{DM}$, thereby contributing $10 \%$ of all TB cases recorded in 2010, a figure that increased to $15 \%$ in $2013 .{ }^{7}$ Low/middle-income countries (LMICs) carry an estimated $80 \%$ and $90 \%$ of DM and TB burden, respectively. ${ }^{6}$ Nine of the top 10 countries identified to have the highest TB-DM incidence, globally, are from LMICs. ${ }^{7}$

The increased risk of TB infections has been associated with DM, which affects the immune system leading to poor treatment outcomes, the likelihood of disease recurrence and 
increased risk of death. ${ }^{8}$ Populations with DM are three to four times more likely to develop $\mathrm{TB}$, as compared with the general populations. ${ }^{28}$ In 2011, the WHO and International Union Against Tuberculosis and Lung Disease (Union) launched a policy framework to address the growing TB-DM co-epidemic, known as the collaborative framework for the management of $\mathrm{TB}$ and $\mathrm{DM} .{ }^{10}$ This framework outlines recommendations to guide countries in the care, prevention, and control of TB and DM worldwide. ${ }^{10}$ The recommendations are to be used by policymakers and implementers to curb the TB-DM co-epidemic and complement the existing systems set up for the prevention and management of TB and DM. ${ }^{3}$ The focus is on: (1) improving detection and management of TB in patients with DM, (2) improving detection and management of DM in patients with TB, and (3) establishing mechanisms of joint coordination at regional, district, and/or local levels (sensitive to country-specific factors), with representation from all relevant stakeholders. ${ }^{10}$

The WHO and Union encourage findings from implementation research to strengthen the existing recommendations for healthcare systems. ${ }^{10}$ In this review, we mapped evidence on the implementation of the WHOUnion collaborative framework, globally. Results from this scoping review provide current data on the state of implementation, reveal existing gaps in current literature and ultimately inform the refinement of questions for further primary research.

\section{METHODS}

\section{Study design}

The methodology for this scoping review, as outlined in the published protocol, ${ }^{11}$ was guided by Arksey and O'Malley's framework and Levac et al $\mathrm{s}^{12}$ methodological enhancement for scoping review projects. ${ }^{13}$ This review mapped literature on the implementation of the WHO collaborative framework for the management of TB-DM comorbidity, published between August 2011 and May 2021. We conducted a systematic search to synthesise published and unpublished literature (grey literature) articles to answer the research question. The research question considered a range of studies including qualitative, quantitative and mixed methods. Arksey and O'Malley's framework gives five clear steps to be used for exploring core concepts in a specific research area. ${ }^{13}$ These steps are: identifying the research question, identifying relevant studies, study selection, charting the data, collating, summarising and reporting the results. ${ }^{13}$ This process helped in identifying the existing evidence in the research area. We also followed guidelines from the Preferred Reporting Items for Systematic Reviews and Meta-Analysis (PRISMA) extension for Scoping Reviews: checklist and explanation for reporting purposes (online supplemental file 1)..$^{14}$

\section{Eligibility of the research question}

This scoping review followed the Population, Concept, Context framework to determine the eligibility of the
Table 1 PCC framework

\begin{tabular}{ll} 
P-Population & $\begin{array}{l}\text { Individuals with TB } \\
\text { Individuals with DM }\end{array}$ \\
\hline C-Concept & $\begin{array}{l}\text { WHO collaborative framework } \\
\text { implementation }\end{array}$ \\
C-Context & Global
\end{tabular}

DM, diabetes mellitus; TB, tuberculosis.

primary research question (table 1). ${ }^{13}$ Based on the framework, the study population was individuals with TB and individuals with DM, the concept was the WHO collaborative framework implementation and the context was global.

\section{Identify the research question}

The main research question: What is the evidence on the implementation of the WHO's TB-DM collaborative framework, globally?

Subquestions:

1. What is the evidence of DM detection and management in patients with TB?

2. What is the evidence of TB detection and management in patients with DM?

3. What is the evidence of collaboration between TB and DM programmes?

4. What is the evidence of a referral system for patients with DM suspected to have TB for diagnosis and management?

5. What is the evidence of a referral system for patients with $\mathrm{TB}$ suspected to have DM for diagnosis and management?

\section{Identifying relevant studies}

Search strategy

We conducted a comprehensive search technique for published and unpublished (grey literature) articles relevant to answer our research question. We piloted our search strategy in December 2019 in PubMed and CINAHL via EBSCOhost, followed by analysis of the text words contained in the title and abstract and of the index terms used to describe the article, guided by the Joanna Briggs Institute's manual for evidence synthesis. ${ }^{15}$ Our overall search was updated in seven electronic databases in May 2021 (online supplemental appendix 1), including: PubMed and CINAHL via EBSCOhost, Web of Science, Science Direct, Scopus, Google Scholar and WHO library. Our search approach included Boolean terms (AND, OR) and Medical Subject Headings terms. The search keywords were: 'Diabetes', 'Type 2 Diabetes', 'Tuberculosis', 'Comorbidity', 'Implementation' and 'Framework'. All studies suitable for inclusion had their reference lists further assessed for potential inclusion. Grey literature articles were accessed by searching for policy documents, treatment guidelines and reports by ministries of health, and health agencies through their websites or links. Studies obtained through database 
searches were exported to EndNote library for further abstract and full article screening, respectively. The 'Find full text' option in the EndNote library was used to automatically obtain PDFs of exported studies.

\section{Study selection}

The first reviewer (RS) conducted the database search based on a broad inclusion criterion. This search focused on the title of the articles. The full texts of all the articles that were selected as potentially eligible for inclusion in this review were obtained. Two independent reviewers (RS and PV) then conducted abstracts and full article screenings in order to identify articles that met all the inclusion criteria. Any disagreements between the two independent reviewers were resolved through discussion. Arrangements had been made for a third reviewer to resolve any disagreements between the two independent reviewers. However, no disagreements emerged, hence the third reviewer was not consulted.

\section{Inclusion and exclusion criteria}

The eligibility criteria were developed to ensure the inclusion of specific information relating to the research questions in the studies. Our inclusion criteria in this review involved studies presenting evidence of TB-DM comorbidity among populations with $\mathrm{TB}$ and $\mathrm{DM}$. We also considered studies presenting evidence of bidirectional screening for $\mathrm{TB}$ and $\mathrm{DM}$, as well as studies presenting evidence of mechanisms of collaboration in the management of TB and DM. All these studies had to be published in English language, between August 2011 and May 2021, given that the framework was first launched in 2011.

Studies presenting evidence on type 1 diabetes and those focusing on TB or HIV were excluded. This review only included articles on type 2 diabetes and excluded type 1 diabetes because type 2 diabetes contributes $90 \%-95 \%$ of all diabetes cases, globally, and shares socioeconomic, environmental, and behavioural factors with TB. ${ }^{16}{ }^{17}$ Also excluded were studies published prior to August 2011 and those published in other languages apart from English language.

\section{Data charting}

To extract relevant information and characteristics of studies, we developed a form electronically, using Google forms, pretested it and used feedback to refine the tool. The selected studies were thoroughly read for data extraction of bibliographical details and ensuring that relevant outcomes were extracted, including: (a) author(s) and date of publication, (b) aim(s) or research questions, (c) primary source data, study population, (d) geographical setting (rural/urban), (e) study design, (f) most relevant finding, (g) most significant finding, (h) study limitations and implications, as well as (i) interpretations and conclusions from the authors.

\section{Collating, summarising and reporting results}

The results from existing studies were summarised and presented in a narrative format. This summary was analysed using thematic content analysis. Data extracted were structured around the following outcomes: bidirectional screening of TB and DM, feasibility of screening and co-management of TB/DM comorbidity. The themes emerging from the analysis were examined to determine whether or not they addressed the research questions. Furthermore, the researchers explored linkages between the findings, study aim, and the implications for future research, policy, and practice.

\section{Quality of evidence}

Two independent reviewers conducted quality assessment by appraising the included studies using the Mixed Method Appraisal Tool (MMAT) V.2018. ${ }^{18}$ The MMAT is a critical appraisal tool designed for the appraisal stage of systematic mixed studies reviews, like reviews that include qualitative, quantitative and mixed-methods studies. The tool may also be used to assess the methodological quality of five different types of studies: qualitative research, randomised controlled trials, non-randomised studies, quantitative descriptive studies and mixed techniques studies (online supplemental appendix 2). The MMAT evaluates the appropriateness of the study aim, study design, methodology including the recruitment of participants, data collection, data analysis, results presentation, authors' discussion and conclusions. Any disagreements between the two independent reviewers were resolved through discussion. The tool does not permit for quality scoring of included studies, therefore we did not provide overall quality scores. ${ }^{18}$

The quality of evidence had little variations across the studies. Most of the 82 studies had good methodological rigour across all the MMAT criteria. Out of the 82 included studies, 4 were poorly appraised; as these studies did not report on the validity and reliability of the measurement, neither did they report on the response rate, hence the risk of non-response bias could not be determined. Furthermore, the sample of the studies was not representative of the target population, as no standard measure was used to determine the sample size. The sample strategy of the studies was not clearly stated, and this could have led to sampling bias. Additionally, one of the mixed-methods studies did not adhere to the quality criteria of each tradition of the methods used in the study.

\section{RESULTS}

The initial search through the electronic databases, including published studies and grey literature, yielded a total of 1442 articles. One thousand and seventy-two (1072) articles were excluded at a database search stage, because they did not meet the inclusion criteria. Sixtyfour duplicates were removed, leaving us with 306 articles that were screened for abstracts. A total of 200 articles were removed at the abstract screening stage based on the exclusion criteria. The researchers further screened the remaining 106 full-text articles and excluded 24 articles (online supplemental appendix 3) with the following 


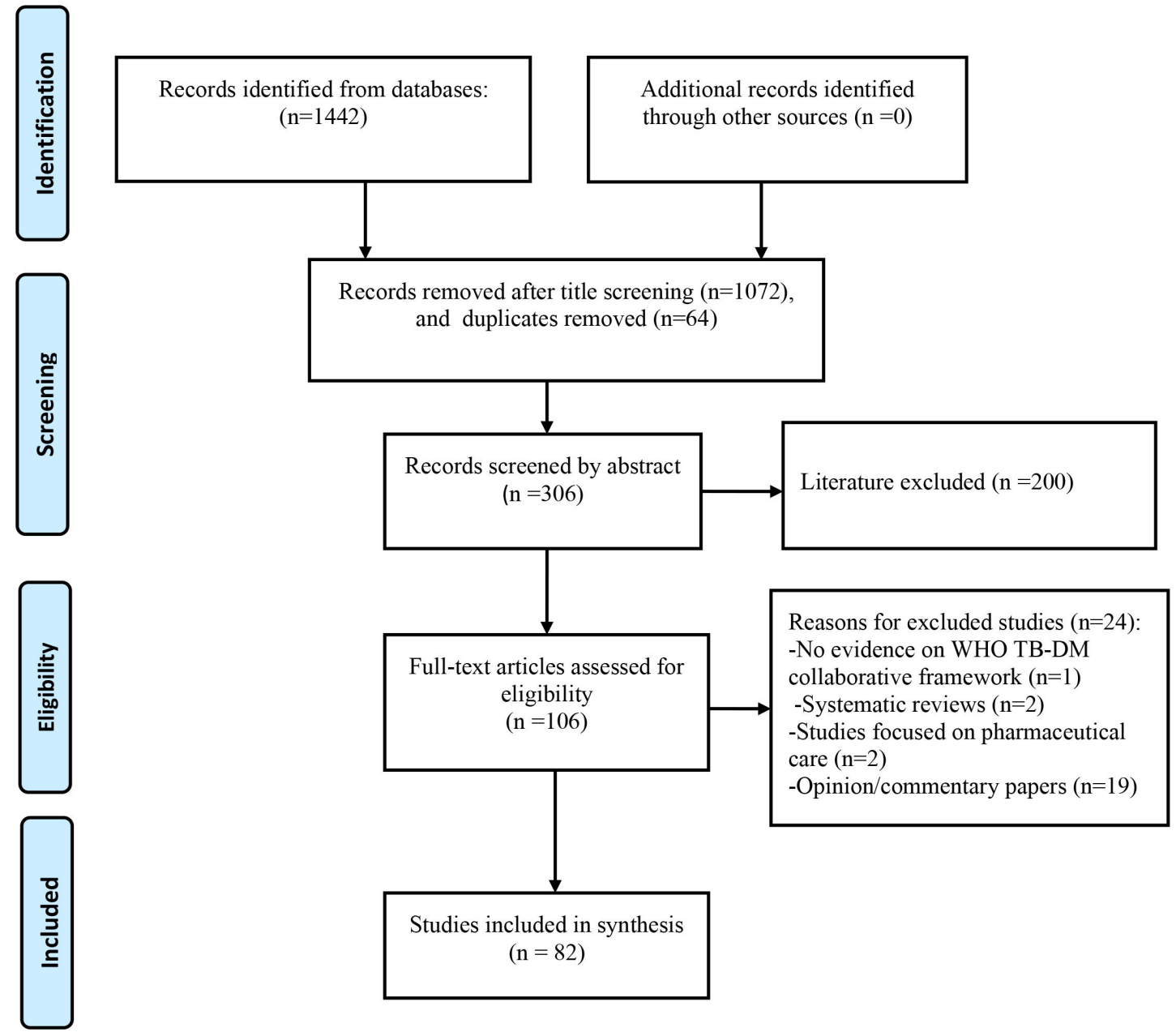

Figure 1 Preferred Reporting Items for Systematic Reviews and Meta-Analysis flow diagram. From: Moher et al. ${ }^{129} \mathrm{DM}$, diabetes mellitus; TB, tuberculosis.

reasons: 19 studies were opinion/commentary papers, 2 were systematic reviews, 2 focused on pharmaceutical care and the last one had no evidence on WHO TB-DM collaborative framework. Figure 1 shows the PRISMA flow diagram demonstrating the screening results from each stage.

\section{Characteristics of included studies}

A total of $82^{9}{ }^{19-98}$ articles from 35 countries including India, China, the USA, Pakistan, Taiwan, Ethiopia, Tanzania and Nigeria met our inclusion criteria and were included in the quality assessment stage. These were 5 qualitative, 75 quantitative and 2 mixed-methods studies. The WHO is made up of 194 member states, but our review found studies from only 35 countries, mostly India $(\mathrm{n}=25),{ }^{19} 2044-5153-555860616381829495$ 99-101 China $(\mathrm{n}=10),{ }^{65-6770} 71848597102$ Ethiopia $(\mathrm{n}=4),{ }^{34} 3594103$ Nigeria $(\mathrm{n}=3)^{25} 3686$ and the USA (n=2). ${ }^{26}{ }^{28}$ Online supplemental appendix 4 summarises the characteristics of the different studies. The findings from this review provided evidence on the feasibility of screening, bidirectional screening (screening patients with TB for DM, screening patients with $\mathrm{DM}$ for $\mathrm{TB}$ ), co-management, and challenges and opportunities, in line with the recommendations of the collaborative framework. ${ }^{10} 104$

\section{Feasibility of screening}

The Bali declaration was expected to accelerate the implementation of the collaborative framework for the care and control of diabetes and TB. ${ }^{104} \mathrm{~A}$ major emphasis was on operational and clinical research, globally, designed to establish evidence to strengthen the current recommendations and propose appropriate indicators. ${ }^{104}$ Our review of publications showed evidence supporting the feasibility of bidirectional screening. Study findings demonstrated that it was possible to conduct screening in both rural and urban settings. ${ }^{55} 68$ The different settings also indicated varying TB-DM prevalence rates in rural and urban regions in various countries. ${ }^{38} 486778$ Additionally, our findings supported routine screening, especially in high-risk populations. ${ }^{20} 2855616365727879$ A predominant number of publications on screening in healthcare settings revealed that screening can be integrated into routine practices in the healthcare system. ${ }^{21} 325360626568-70819899$ 105-107 


\section{Bidirectional screening}

One of the public health actions proposed for averting the impact of the looming TB-DM co-epidemic is screening patients with $\mathrm{TB}$ for $\mathrm{DM}$ and vice-versa. ${ }^{104}$ This review identified publications on screening to provide evidence on suitable approaches used by various countries and settings. Majority $(60 \%)$ of the included studies focused on screening patients with TB for $\mathrm{DM}^{19} 202228$ 34-36 384041 46-51 57 5961 65-67 71 72 76-80 82 108-112

a phenomenon that permeated throughout various countries spreading across the five geographical regions, especially Asia. The DM prevalence among patients with $\mathrm{TB}$ varied within countries, such as India $(5 \%-25 \%)^{19} 204648515458596182$ and China (6.3\%$12.4 \%) .{ }^{65} \mathrm{DM}$ prevalence was reported by the studies to be higher in older male patients with TB than female counterparts and mostly in urban settings. 194672113

Fewer studies focused on screening patients with DM for $\mathrm{TB}$, and this was attributed to the low availability of TB management strategies in DM facilities. 3368708186100114 These studies were conducted in the USA, India, Tanzania, Korea, Bangladesh, China, Taiwan, Nigeria and Iran. Generally, the risk of TB in patients with DM is about three times higher compared with the general population, a pattern that was also confirmed in our review. ${ }^{16115}$ Results ranged from as low as 1.8-fold in South Korea to 7-fold in Tanzania, higher than the general population. ${ }^{2162}$ In one study conducted in India, TB was not prevalent among patients with DM. ${ }^{53}$ Male patients with DM were found to be at increased risk of TB than their female counterparts. $^{2126526070}$ Higher TB rates among older men were attributable to sedentary lifestyles, high body mass index (BMI) levels and smoking practice. ${ }^{6070}$ Age and gender were identified as important risk factors for TB. ${ }^{60}$

\section{Co-management}

Several studies highlighted the minimum or lack of integration between TB and DM units and the parallel paths of care for patients with TB-DM comorbidity. This is shown by the quotes below:

Endocrinologist treats diabetes, and we treat TB (p4). ${ }^{37}$

We treat diabetes and that's it (p6). ${ }^{37}$

Since our main task is TB treatment, the primary treatment is focused on TB (p6). ${ }^{37}$

A TB patient should have tests for diabetes but generally diabetes patients don't go for TB tests $(\mathrm{p} 7) .{ }^{100}$

There was more evidence on case detection than co-management of TB and DM. ${ }^{29}{ }^{37}$ Patients with TB-DM comorbidity did not appear to receive comparable treatment, and this may be due to more funding being available to TB, compared with diabetes and the limited number of staff trained in co-management. ${ }^{37114}$

We haven't received any funding or training, especially for this screening...I think, currently the training is not adequate. It should be given more often $(\mathrm{p} 7) .{ }^{100}$
Individuals with the dual TB-DM condition were found to have better outcomes when jointly managed. ${ }^{114}$

\section{Opportunities and challenges}

Implementation of the collaborative framework in various countries revealed the opportunities and challenges among healthcare workers, patients and the healthcare system. One of the opportunities identified was the feasibility to implement screening in the existing healthcare systems. ${ }^{22}{ }^{72}$ However, it is still important that policies that support integrated screening in routine health service delivery be developed. ${ }^{78}$ Timely diagnosis and management of TB-DM comorbidity were improved by implementing cost-effective measures, recording screening and user-friendly approaches. ${ }^{22} 6072788099$ Some of the challenges encountered were lack of awareness of bidirectional screening by patients, while some healthcare providers were not aware of guidelines for bidirectional screening. ${ }^{56}$

See madam, what can I tell about this [screening for $\mathrm{DM}$ ]? Doctors can only talk about this [screening TB patients for DM] $(\mathrm{p} 7) .^{56}$

I don't know about that [any national guidelines] $(\mathrm{p} 7) .^{56}$

\section{DISCUSSION}

This scoping review mapped existing literature on the implementation of the TB-DM collaborative framework, globally, and provides an overview of the extent of implementation from 2011 to 2021. Our review found evidence of research in 35 countries, predominantly from LMICs. India and China showed greatest research outputs on the implementation of the collaborative framework, and this may be due to high TB burden being observed in these countries. ${ }^{1067}$ Findings pointed to the feasibility of bidirectional screening, opportunities and challenges, as well as fewer publications on the collaboration of TB and DM programmes, thereby highlighting gaps in evidence on the integration of services for the management of TB-DM comorbidity.

Several studies in this review focused on screening patients with $\mathrm{TB}$ for $\mathrm{DM}$ as compared with screening patients with $\mathrm{DM}$ for $\mathrm{TB}$ and this was congruent with the findings of Workneh et al. ${ }^{103}$ Additionally, there were limited articles on screening patients with TB for DM in African countries and this was consistent with what had been reported in a prior study conducted in Ghana. ${ }^{39}$ This is probably because of inadequate support for DM facilities to screen for TB. Fewer articles showed evidence of screening both patients with TB and patients with DM in the same study. This review showed that screening can be implemented in both urban and rural settings with varying prevalence rates across geographical settings, thereby rendering the link between prevalence and the type of setting (rural vs urban) weak. This is in contrast with the findings of the study by Sulaiman et al, who 
found prevalence rates to be the same in urban and rural centres. ${ }^{116}$

Bidirectional screening was found to be mainly implemented in healthcare facilities and this revealed that the existing healthcare systems can be used to co-manage individuals with TB-DM comorbidity, similar to findings by a review conducted in India. ${ }^{117}$ Routine screening in high-risk populations was demonstrated by some studies in our review and was linked to early detection of $\mathrm{TB}$ or DM, subsequently leading to more effective management and outcomes. This was also reported in other studies. ${ }^{16} 192260118$

The risk of patients with DM developing TB has been estimated to be threefold as compared with the general population. ${ }^{10}$ While this was generally confirmed by the findings of this review, two studies produced contrary findings, which revealed low DM prevalence in patients with $\mathrm{TB} .{ }^{27} 76$ Therefore, evidence suggesting that DM is a risk factor for TB remains inconclusive and further studies are required.

Consistent with recommendations from other studies, evidence from this review points to the need for more awareness on bidirectional screening for both patients and healthcare workers. ${ }^{46} 5467119$ Individuals with the coinfection were not found to be receiving comparable care for each disease, which may be contributing to the growing TB-DM comorbidity and adversely affecting the global efforts towards the control of TB. ${ }^{37} 7778120$

A key recommendation by the WHO-Union collaborative framework is joint management to improve health outcomes of patients with TB-DM comorbidity. ${ }^{10}$ Health systems in this review were having challenges in managing TB and DM jointly, due to existing systems of care that offered vertical healthcare, ${ }^{37} 114$ which is supported by a review on the double burden of TB and DM. ${ }^{121}$ The silo approach in most healthcare systems with regard to communicable and non-communicable diseases was a barrier to integrating care for individuals with the dual condition. Although not identified in this research, an article published in India showed that collaboration is also hindered due to patients with TB being largely managed in public health facilities, as compared with patients with DM, who are mostly being cared for in private health facilities. $^{122}$

Some studies have shown that individuals with coinfection have different experiences of care in health facilities, when compared with patients with only one condition. ${ }^{56} 114$ Their experiences spanned from the unavailability of joint consultation, so patients had to see a separate specialist for the different conditions, to the indecisiveness of health workers on whether to admit individuals with the comorbidity in DM or TB wards. ${ }^{37114}$ This may be due to the perception that TB-DM comorbidity is a complicated condition that may lead to relapse, treatment failure, or death and requiring specialist attention. ${ }^{37} 123124$ Patients and healthcare professionals had to find ways to integrate required medication, addressing medication-related issues, and more education to help patients understand the comorbidity. ${ }^{114}$ There is a need for clear guidelines, diagnostics and refresher training for healthcare workers. ${ }^{14} 125$ Other studies support our findings that joint management improves early diagnosis and health outcomes. ${ }^{16} 126$

\section{Limitations}

Our review is subject to important limitations. This review included only articles published in English language, which may have excluded some relevant studies published in other languages. We only identified one non-English article, which was in Spanish, and this too may be reflective of our incompetence in other languages. Only a single reviewer carried out title and abstract screening. The database search conducted by two independent reviewers may have yielded additional relevant studies. Despite the generally relevant key words used while searching for relevant articles in different databases, other terms may also exist. Nonetheless, the study strictly followed the framework provided by Arksey and O'Malley's framework to map evidence on the implementation of the WHO's collaborative framework for the management of TB and diabetes comorbidity, globally. Despite these limitations, we believe that our search strategy was comprehensive in reviewing relevant literature for this review.

\section{Implications for practice}

In line with other recommendations, ${ }^{127}$ our findings suggest that free glucose tests, integration of DM and TB services, patient counselling and routine screening are factors that enhance effective screening. ${ }^{47}{ }^{57}$ In areas where bidirectional screening was not effective, factors such as inadequate staffing, poor supply of laboratory supplies for DM diagnosis and poor patient awareness of bidirectional screening were highlighted. ${ }^{56}$ Recommendations from screening studies emphasise the importance of policies that support integrating screening in routine health delivery, cost-effective measures, recording screening results in reports and user-friendly approaches, to improve timely diagnosis and management. ${ }^{80} 128$

\section{Conclusion}

This review revealed that bidirectional screening is feasible and can potentially improve the diagnosis and co-management of individuals with TB and DM. Additionally, the study demonstrates that gaps still exist in research aimed at providing evidence of improved techniques for detecting TB-DM comorbidity. There is an urgent need for health systems to integrate TB and DM services.

Acknowledgements We are grateful to the University of KwaZulu-Natal, College of Health Sciences, for providing us with vital research resources to complete this manuscript. We would also like to appreciate the staff of the Department of Public Health Medicine, the University of KwaZulu-Natal for their diverse support. We thank Portia Vezi for co-screening the articles for this scoping review.

Contributors RSS conceptualised the study and wrote the first draft. $\mathrm{MH}$ and $\mathrm{KH}$ contributed to the writing and critically reviewed the draft. RSS wrote the final manuscript, and all authors approved the final draft. RSS is responsible for the overall content as the guarantor. 
Funding This work was supported by the University of KwaZulu-Natal, College of Health Sciences Research Scholarship (grant number CS3130726).

Competing interests None declared.

Patient consent for publication Not required.

Ethics approval Since this review used a secondary synthesis of data, which is already in the public domain, ethical approvals and consent to participate were not applicable.

Provenance and peer review Not commissioned; externally peer reviewed.

Data availability statement All data relevant to the study are included in the article or uploaded as supplemental information. We have duly cited all studies, and data is presented in a form of references.

Supplemental material This content has been supplied by the author(s). It has not been vetted by BMJ Publishing Group Limited (BMJ) and may not have been peer-reviewed. Any opinions or recommendations discussed are solely those of the author(s) and are not endorsed by BMJ. BMJ disclaims all liability and responsibility arising from any reliance placed on the content. Where the content includes any translated material, BMJ does not warrant the accuracy and reliability of the translations (including but not limited to local regulations, clinical guidelines, terminology, drug names and drug dosages), and is not responsible for any error and/or omissions arising from translation and adaptation or otherwise.

Open access This is an open access article distributed in accordance with the Creative Commons Attribution Non Commercial (CC BY-NC 4.0) license, which permits others to distribute, remix, adapt, build upon this work non-commercially, and license their derivative works on different terms, provided the original work is properly cited, appropriate credit is given, any changes made indicated, and the use is non-commercial. See: http://creativecommons.org/licenses/by-nc/4.0/.

\section{ORCID iDs}

Rita Suhuyini Salifu http://orcid.org/0000-0001-6508-6915

Mbuzeleni Hlongwa http://orcid.org/0000-0002-5352-5658

\section{REFERENCES}

1 Jeon $\mathrm{CY}$, Murray MB. Diabetes mellitus increases the risk of active tuberculosis: a systematic review of 13 observational studies. PLoS Med 2008;5:e152.

2 Al-Rifai RH, Pearson F, Critchley JA, et al. Association between diabetes mellitus and active tuberculosis: a systematic review and meta-analysis. PLoS One 2017;12:e0187967.

3 Kapur A, Harries AD, Lönnroth K, et al. Diabetes and tuberculosis co-epidemic: the Bali Declaration. Lancet Diabetes Endocrinol 2016;4:8-10.

4 World Health Organization. Global tuberculosis report 2020, 2020.

5 World Health Organization. Diabetes - WHO, 2021. Available: https://www.who.int

6 Mbanya JCN, Motala AA, Sobngwi E, et al. Diabetes in sub-Saharan Africa. Lancet 2010;375:2254-66.

7 Lönnroth K, Roglic G, Harries AD. Improving tuberculosis prevention and care through addressing the global diabetes epidemic: from evidence to policy and practice. Lancet Diabetes Endocrinol 2014;2:730-9.

8 Reid MJA, McFadden N, Tsima BM. Clinical challenges in the co-management of diabetes mellitus and tuberculosis in southern Africa. J Endocrinol 2013;18:135-40.

9 Workneh MH, Bjune GA, Yimer SA. Prevalence and associated factors of diabetes mellitus among tuberculosis patients in southeastern Amhara region, Ethiopia: a cross sectional study. PLoS One 2016;11:e0147621.

10 World Health Organization. Collaborative framework for care and control of tuberculosis and diabetes. World Health Organization, 2011.

11 Quist-Therson R, Kuupiel D, Hlongwana K. Mapping evidence on the implementation of the WHO's collaborative framework for the management of tuberculosis and diabetes: a scoping review protocol. BMJ Open 2020;10:e033341.

12 Levac D, Colquhoun H, O'Brien KK. Scoping studies: advancing the methodology. Implement Sci 2010;5:1-9.

13 Arksey H, O'Malley L. Scoping studies: towards a methodological framework. Int J Soc Res Methodol 2005;8:19-32.

14 Tricco AC, Lillie E, Zarin W, et al. PRISMA extension for scoping reviews (PRISMA-ScR): checklist and explanation. Ann Intern Med 2018;169:467-73.
15 Institute JB. JBI manual for evidence synthesis, 2020. Available: https://wiki.jbi.global/site/JGW

16 Harries AD, Kumar AMV, Satyanarayana S, et al. Addressing diabetes mellitus as part of the strategy for ending TB. Trans $R$ Soc Trop Med Hyg 2016;110:173-9.

17 Maurice J. WHO framework targets tuberculosis-diabetes link. Lancet 2011;378:1209-10.

18 Hong QN, Fàbregues S, Bartlett G, et al. The mixed methods appraisal tool (MMAT) version 2018 for information professionals and researchers. Educat Inform 2018;34:285-91.

19 Balakrishnan S, Vijayan S, Nair S, et al. High diabetes prevalence among tuberculosis cases in Kerala, India. PLoS One 2012;7:e46502.

20 Achanta S, Tekumalla RR, Jaju J, et al. Screening tuberculosis patients for diabetes in a tribal area in South India. Public Health Action 2013;3:43-7.

21 Heo EY, Choi N-K, Yang BR, et al. Tuberculosis is frequently diagnosed within 12 months of diabetes mellitus. Int $J$ Tuberc Lung Dis 2015;19:1098-101.

22 Gounder S, Harries AD. Screening tuberculosis patients for diabetes mellitus in Fiji: notes from the field. Public Health Action 2012;2:145-7.

23 Castellanos-Joya M, Delgado-Sánchez G, Ferreyra-Reyes L, et al. Results of the implementation of a pilot model for the bidirectional screening and joint management of patients with pulmonary tuberculosis and diabetes mellitus in Mexico. PLoS One 2014;9:e106961.

24 O'Jiaku-Okorie A. The prevalence and determinants of active tuberculosis among diabetes patients attending a primary health care clinic in Cape Town, South Africa. University of Cape Town, 2016.

25 Ogbera OA, Adeyeye O, Odeniyi IA, et al. Knowledge of diabetes mellitus in tuberculosis amongst healthcare workers in Nigeria. Indian J Endocrinol Metab 2013;17:704.

26 Demlow SE, Oh P, Barry PM. Increased risk of tuberculosis among foreign-born persons with diabetes in California, 2010-2012. BMC Public Health 2015;15:1-8.

27 Ade S, Affolabi D, Agodokpessi G, et al. Low prevalence of diabetes mellitus in patients with tuberculosis in Cotonou, Benin. Public Health Action 2015;5:147-9.

28 Suwanpimolkul G, Grinsdale JA, Jarlsberg LG, et al. Association between diabetes mellitus and tuberculosis in United Statesborn and foreign-born populations in San Francisco. PLoS One 2014;9:e114442.

29 Basir MS, Habib SS, Zaidi SMA, et al. Operationalization of bidirectional screening for tuberculosis and diabetes in private sector healthcare clinics in Karachi, Pakistan. BMC Health Serv Res 2019;19:1-9.

30 Jabbar A, Hussain SF, Khan AA. Clinical characteristics of pulmonary tuberculosis in adult Pakistani patients with co-existing diabetes mellitus. East Mediterr Health J 2006;12:522-7.

31 Viney K, Cavanaugh J, Kienene T, et al. Tuberculosis and diabetes mellitus in the Republic of Kiribati: a case-control study. Trop Med Int Health 2015;20:650-7.

32 Alavi SM, Khoshkhoy MM. Pulmonary tuberculosis and diabetes mellitus: co-existence of both diseases in patients admitted in a teaching hospital in the southwest of Iran. Caspian J Intern Med 2012;3:421.

33 Daru P, Chakraborty K, AlMossawi H, et al. Active tuberculosis case finding among diabetic patients: Bangladesh program experience. $J$ Infect Dis Diagn 2019;4:2.

34 Workneh MH, Bjune GA, Yimer SA. Assessment of health system challenges and opportunities for possible integration of diabetes mellitus and tuberculosis services in South-Eastern Amhara Region, Ethiopia: a qualitative study. BMC Health Serv Res 2016;16:1-11.

35 Tenaye L, Mengiste B, Baraki N, et al. Diabetes mellitus among adult tuberculosis patients attending tuberculosis clinics in eastern Ethiopia. Biomed Res Int 2019;2019:1-7.

36 Ojule I, Opara A. Fasting blood glucose profile of tuberculosis patients in Port Harcourt, Nigeria. Port Harcourt Med J 2019;13:26.

37 Skordis-Worrall J, Round J, Arnold M, et al. Addressing the doubleburden of diabetes and tuberculosis: lessons from Kyrgyzstan. Global Health 2017;13:1-9.

38 Mahato RK, Laohasiriwong W, Koju R. The role of type 2 diabetes mellitus on the clinical manifestation of pulmonary tuberculosis: a study from Nepal. JCDR 2019;13:9-14.

39 Asante-Poku A, Asare P, Baddoo NA, et al. TB-diabetes comorbidity in Ghana: the importance of Mycobacterium africanum infection. PLoS One 2019;14:e0211822. 
40 Rajapakshe W, Isaakidis P, Sagili KD, et al. Screening patients with tuberculosis for diabetes mellitus in Ampara, Sri Lanka. Public Health Action 2015;5:150-2.

41 Lu CL, Perera R, Farrah H, et al. Diabetes screening among active tuberculosis patients in Western Australia tuberculosis control program using HbA1c. Intern Med J 2019;49:630-3.

42 Pearson F, Huangfu P, McNally R, et al. Tuberculosis and diabetes: bidirectional association in a UK primary care data set. $J$ Epidemiol Community Health 2019;73:142-7.

43 Hadžić V, Abdulović E, Hasanović E. The link between active pulmonary tuberculosis and high blood glucose level. Respiratio.

44 Anand T, Kishore J, Isaakidis P, et al. Integrating screening for non-communicable diseases and their risk factors in routine tuberculosis care in Delhi, India: a mixed-methods study. PLoS One 2018;13:e0202256.

45 Kumpatla S, Sekar A, Achanta S, et al. Characteristics of patients with diabetes screened for tuberculosis in a tertiary care hospital in South India. Public Health Action 2013;3:23-8.

46 Nagar V, Gour D, Arutagi V, et al. A study to assess the blood glucose level among diagnosed cases of tuberculosis registered at a tuberculosis unit of Bhopal City, Madhya Pradesh, India. Int J Med Sci Public Health 2015;4:245-9.

47 Tiwari VK, Verma P, Raj S. Factors associated with diabetes mellitus among tuberculosis patients attending tertiary care hospital in Delhi, India. Ind J Comm Health 2016;28:369-73.

48 Dave P, Shah A, Chauhan M, et al. Screening patients with tuberculosis for diabetes mellitus in Gujarat, India. Public Health Action 2013:3:29-33.

49 Pande T, Huddart S, Xavier W, et al. Prevalence of diabetes mellitus amongst hospitalized tuberculosis patients at an Indian tertiary care center: a descriptive analysis. PLoS One 2018;13:e0200838.

50 Gupte AN, Mave V, Meshram S, et al. Trends in HbA1c levels and implications for diabetes screening in tuberculosis cases undergoing treatment in India. Int J Tuberc Lung Dis 2018;22:800-6.

51 Verma P, Tiwari V, SR TP. Twin burden of co-morbidity (TB with DM): awareness and effect of diabetes mellitus (DM) on treatment outcome of tuberculosis among patients attending TB clinic in a tertiary care hospital in Delhi. Indian J Prevent Soc Med 2016;47:11.

52 Dutt N, Gupta A. A study on diabetes mellitus among cases of pulmonary tuberculosis in a tertiary care Hospital, Ahmedabad. National J Med Res 2014;4:349-53.

53 Mave V, Nimkar S, Prasad H, et al. Tuberculosis screening among persons with diabetes mellitus in Pune, India. BMC Infect Dis 2017;17:1-5.

54 Agarwal AK, Gupta G, Marskole P, et al. A study of the patients suffering from tuberculosis and tuberculosis-diabetes comorbidity in revised national tuberculosis control program centers of Northern Madhya Pradesh, India. Indian J Endocrinol Metab 2017;21:570-6.

55 Prakash BC, Ravish KS, Prabhakar B, et al. Tuberculosis-diabetes mellitus bidirectional screening at a tertiary care centre, South India. Public Health Action 2013;3:18-22.

56 Majumdar A, Wilkinson E, Rinu PK, et al. Tuberculosis-diabetes screening: how well are we doing? A mixed-methods study from North India. Public Health Action 2019;9:3-10.

57 Kottarath M, Mavila R, V. A, Achuthan V, et al. Prevalence of diabetes mellitus in tuberculosis patients: a hospital based study. Int J Res Med Sci 2015;3:2810-4.

58 Manjareeka M, Palo SK, Swain S, et al. Diabetes mellitus among newly diagnosed tuberculosis patients in tribal Odisha: an exploratory study. J Clin Diagn Res 2016;10:LC06.

59 Raghuraman S, Vasudevan KP, Govindarajan S, et al. Prevalence of diabetes mellitus among tuberculosis patients in urban Puducherry. N Am J Med Sci 2014;6:30.

60 Hussain T, Bhuyan K, Prusty B, et al. Incidence and risk factors of tuberculosis among patients with type 2 diabetes mellitus attending a tertiary care hospital in Bhubaneswar, Odisha.

61 Naik B, Kumar AMV, Satyanarayana S, et al. Is screening for diabetes among tuberculosis patients feasible at the field level? Public Health Action 2013:3:34-7.

62 Mtwangambate G, Kalluvya SE, Kidenya BR, et al. 'Coughtriggered' tuberculosis screening among adults with diabetes in Tanzania. Diabet Med 2014;31:600-5.

63 Jali MV, Mahishale VK, Hiremath MB. Bidirectional screening of tuberculosis patients for diabetes mellitus and diabetes patients for tuberculosis. Diabetes Metab J 2013;37:291.

64 Faurholt-Jepsen D, Range N, Praygod G, et al. The role of diabetes co-morbidity for tuberculosis treatment outcomes: a prospective cohort study from Mwanza, Tanzania. BMC Infect Dis 2012;12:1-8.

$65 \mathrm{Li} \mathrm{L}$, Lin Y, Mi F, et al. Screening of patients with tuberculosis for diabetes mellitus in China. Trop Med Int Health 2012;17:1294-301.
66 Wang Q, Ma A, Han X, et al. Prevalence of type 2 diabetes among newly detected pulmonary tuberculosis patients in China: a community based cohort study. PLoS One 2013;8:e82660.

67 Zhao Q, Xiao X, Lu W, et al. Screening diabetes in tuberculosis patients in eastern rural China: a community-based cross-sectional study. Int J Tuberc Lung Dis 2016;20:1370-6.

68 Lin Y, Innes A, Xu L. Screening of patients with D iabetes M ellitus for T uberculosis in $\mathrm{C}$ ommunity $\mathrm{H}$ ealth $\mathrm{S}$ ettings in China 2015;20:1073-80.

69 Lin Y, Li L, Mi F, et al. Screening patients with diabetes mellitus for tuberculosis in China. Tropical Medicine \& International Health 2012:17:1302-8.

70 Qiu H, Shi Y, Li Y, et al. Incident rate and risk factors for tuberculosis among patients with type 2 diabetes: retrospective cohort study in Shanghai, China. Trop Med Int Health 2017;22:830-8.

71 Lin Y, Yuan Y, Zhao X, et al. The change in blood glucose levels in tuberculosis patients before and during anti-tuberculosis treatment in China. Glob Health Action 2017;10:1289737.

72 Nasa JN, Brostrom R, Ram S, et al. Screening adult tuberculosis patients for diabetes mellitus in Ebeye, Republic of the Marshall Islands. Public Health Action 2014;4:50-2.

73 Ko P-Y, Lin S-D, Tu S-T, et al. High diabetes mellitus prevalence with increasing trend among newly-diagnosed tuberculosis patients in an Asian population: a nationwide population-based study. Prim Care Diabetes 2016;10:148-55.

74 Lin C-H, Kuo S-C, Hsieh M-C, et al. Effect of diabetes mellitus on risk of latent TB infection in a high TB incidence area: a communitybased study in Taiwan. BMJ Open 2019;9:e029948.

75 Araia ZZ, Mebrahtu AH, Tewelde AG, et al. TB-diabetes comorbidity and associated factors in Maekel Zone. Eritrea: A cross sectional study, 2019.

76 Haraldsdottir TL, Rudolf F, Bjerregaard-Andersen M, et al. Diabetes mellitus prevalence in tuberculosis patients and the background population in Guinea-Bissau: a disease burden study from the capital Bissau. Trans R Soc Trop Med Hyg 2015;109:400-7.

77 Hoa NB, Phuc PD, Hien NT, et al. Prevalence and associated factors of diabetes mellitus among tuberculosis patients in Hanoi, Vietnam. BMC Infect Dis 2018;18:603.

78 Ncube RT, Dube SA, Machekera SM, et al. Feasibility and yield of screening for diabetes mellitus among tuberculosis patients in Harare, Zimbabwe. Public Health Action 2019:9:72-7.

79 Pablo-Villamor MP, Benedicto JP, Benedicto M, et al. Screening for diabetes mellitus in patients diagnosed with pulmonary tuberculosis. Philipp J Intern Med 2014;52:1-9.

80 Fwoloshi S, Hachaambwa LM, Chiyeñu KO, et al. Screening for diabetes mellitus among tuberculosis patients: findings from a study at a tertiary hospital in Lusaka, Zambia. Canad J Infect Dis Med Microbiol 2018;2018:1-5.

81 Mave V, Meshram S, Lokhande R, et al. Prevalence of dysglycemia and clinical presentation of pulmonary tuberculosis in Western India. Int J Tuberc Lung Dis 2017;21:1280-7.

82 India Tuberculosis-Diabetes Study Group. Screening of patients with tuberculosis for diabetes mellitus in India. Trop Med Int Health 2013:18:636-45.

83 Arini M, Sugiyo D, Permana I. Challenges, opportunities, and potential roles of the private primary care in tuberculosis and diabetes mellitus (TB-DM) collaborative care and control: a qualitative study 2021

84 Xiao W, Huang D, Li S, et al. Delayed diagnosis of tuberculosis in patients with diabetes mellitus co-morbidity and its associated factors in Zhejiang Province, China. BMC Infect Dis 2021;21:1-10.

85 Bei C, Deng P, Yang F. Tuberculosis screening among patients with diabetes mellitus: is it necessary and how should it be done?-A survey of endocrinologists in Hunan Province, China 2020.

86 Ekeke N, Aniwada E, Chukwu J, et al. Screening diabetes mellitus patients for tuberculosis in Southern Nigeria: A pilot study. Adv Respir Med 2020;88:6-12.

87 Kyaw Soe T, Soe KT, Satyanarayana S, et al. Gaps in implementing bidirectional screening for tuberculosis and diabetes mellitus in Myanmar: an operational research study. Trop Med Infect Dis 2020;5:19.

88 Habib SS, Rafiq S, Jamal WZ, et al. Engagement of private healthcare providers for case finding of tuberculosis and diabetes mellitus in Pakistan. BMC Health Serv Res 2020;20:1-8.

89 Araia ZZ, Mesfun AB, Mebrahtu AH. Prevalence and related factors of diabetes mellitus in tuberculosis patients in Maekel region, Eritrea: a cross-sectional study.

90 Gezahegn H, Ibrahim M, Mulat E. Diabetes mellitus and tuberculosis comorbidity and associated factors among bale zone health institutions, Southeast Ethiopia. Diabetes Metab Syndr Obes 2020;13:3879-86. 
91 Ugarte-Gil C, Alisjahbana B, Ronacher K, et al. Diabetes mellitus among pulmonary tuberculosis patients from 4 tuberculosisendemic countries: the TANDEM study. Clin Infect Dis 2020;70:780-8.

$92 \mathrm{MM} \mathrm{O}$, Tassanakijpanich N, Phyu MH, et al. Coverage of tuberculosis and diabetes mellitus screening among household contacts of tuberculosis patients: a household-based crosssectional survey from Southern Thailand. BMC Public Health 2020;20:1-10.

93 Salifu RS, Hlongwana KW. Barriers and facilitators to bidirectional screening of TB-DM in Ghana: healthcare workers' perspectives. PLoS One 2020;15:e0235914.

94 Gurukartick J, Murali L, Shewade HD, et al. Glycemic control monitoring in patients with tuberculosis and diabetes: a descriptive study from programmatic setting in Tamil Nadu, India. F1000Res 2019;8:1725.

95 Sembiah S, Nagar V, Gour D, et al. Diabetes in tuberculosis patients: an emerging public health concern and the determinants and impact on treatment outcome. J Family Community Med 2020;27:91.

96 Hewage S, Somasundaram N, Ratnasamy V, et al. Active screening of patients with diabetes mellitus for pulmonary tuberculosis in a tertiary care hospital in Sri Lanka. PLoS One 2021;16:e0249787.

$97 \mathrm{Ji} \mathrm{Y,} \mathrm{Cao} \mathrm{H,} \mathrm{Liu} \mathrm{Q,} \mathrm{et} \mathrm{al.} \mathrm{Screening} \mathrm{for} \mathrm{pulmonary} \mathrm{tuberculosis} \mathrm{in}$ high-risk groups of diabetic patients. Int $J$ Infect Dis 2020;93:84-9.

98 Trinidad RM, Brostrom R, Morello Ml, et al. Tuberculosis screening at a diabetes clinic in the Republic of the Marshall islands. J Clin Tuberc Other Mycobact Dis 2016;5:4-7.

99 Dutt N, Gupta A. A study on diabetes mellitus among cases of pulmonary tuberculosis in a tertiary care Hospital, Ahmedabad.

100 Majumdar A, Wilkinson E, Rinu PK, et al. Tuberculosis-diabetes screening: how well are we doing? A mixed-methods study from North India. Public Health Action 2019;9:3-10.

101 Kottarath M, Mavila R, V. A, Achuthan V, et al. Prevalence of diabetes mellitus in tuberculosis patients: a hospital based study. Int J Res Med Sci 2015:2810-4.

102 Lin Y, Harries AD. Tuberculosis infection control measures in diabetes clinics in China: a rapid assessment of 10 hospitals. Trop Med Int Health 2015;20:1196-200.

103 Workneh MH, Bjune GA, Yimer SA. Prevalence and associated factors of tuberculosis and diabetes mellitus comorbidity: a systematic review. PLoS One 2017:12:e0175925.

104 Kapur A, Harries AD, Lönnroth K, et al. Sulistyowati LSJTID, endocrinology. Diabetes and tuberculosis co-epidemic: the Bali Declaration 2016;4:8-10.

105 Deng C, Wang X, Liao Y. Current recommendations on managing tuberculosis patients with diabetes \& its epidemiology. Microb Pathog 2016;92:43-5.

106 Rahmanian V, Rahmanian K, Mansoorian E, et al. Prevalence of active tuberculosis \& MTB-infection among diabetic population in southern of Iran, 2016. Pharmacophore 2018;9:30-6.

107 Huangfu P, Ugarte-Gil C, Golub J, et al. The effects of diabetes on tuberculosis treatment outcomes: an updated systematic review and meta-analysis. Int J Tuberc Lung Dis 2019;23:783-96.

108 Wang Q, Han X, Ma A, et al. Screening and intervention of diabetes mellitus in patients with pulmonary tuberculosis in poverty zones in China: rationale and study design. Diabetes Res Clin Pract 2012;96:385-91.

109 Restrepo BI, Camerlin AJ, Rahbar MH, et al. Cross-sectional assessment reveals high diabetes prevalence among newlydiagnosed tuberculosis cases. Bull World Health Organ 2011;89:352-9.

110 Sariko ML, Mpagama SG, Gratz J, et al. Glycated hemoglobin screening identifies patients admitted for retreatment of tuberculosis at risk for diabetes in Tanzania. $J$ Infect Dev Ctries 2016;10:423-6.

111 Ekeke N, Ukwaja KN, Chukwu JN, et al. Screening for diabetes mellitus among tuberculosis patients in Southern Nigeria: a multicentre implementation study under programme settings. Sci Rep 2017;7:1-8.

112 Ekeke N, Ukwaja KN, Chukwu JN, et al. Screening for diabetes mellitus among tuberculosis patients in Southern Nigeria: a multicentre implementation study under programme settings. Sci Rep 2017;7:44205.

113 Ogbera AO, Kapur A, Abdur-Razzaq H, et al. Clinical profile of diabetes mellitus in tuberculosis. BMJ Open Diabetes Res Care 2015;3:e000112.

114 Shayo FK, Shayo SC. Availability and readiness of diabetes health facilities to manage tuberculosis in Tanzania: a path towards integrating tuberculosis-diabetes services in a high burden setting? BMC Public Health 2019;19:1104.

115 Lönnroth K. Colliding epidemics requires collaborating programmes. Lancet Diabetes Endocrinol 2015;3:306-7.

116 Sulaiman SAS, Zain FAM, Majid SA. Tuberculosis among diabetic patient. Webmed Central Infect Dis 2011

117 Samal J. Screening of tuberculosis patients for possible diabetes mellitus in India: a systematic review. Egypt $J$ Broncho 2017;11:1-6.

118 Cadena J, Rathinavelu S, Lopez-Alvarenga JC, et al. The reemerging association between tuberculosis and diabetes: lessons from past centuries. Tuberculosis 2019;116S:S89-97.

119 Deng C, Wang X, YJMp L. Current recommendations on managing tuberculosis patients with diabetes \& its epidemiology 2016;92:43-5.

120 Sarker M, Barua M, Guerra F, et al. Double trouble: prevalence and factors associated with tuberculosis and diabetes comorbidity in Bangladesh. PLoS One 2016;11:e0165396.

121 Kapur A, Harries AD. The double burden of diabetes and tuberculosis-public health implications. Diabetes Res Clin Pract 2013;101:10-19.

122 Sharma P, Visnegarwala F, Tripathi V. Burgeoning double burden of tuberculosis and diabetes in India: magnitude of the problem - strategies and solutions. Clin Epidemiol Glob Health 2014;2:107-16.

123 Lee P-H, Lin H-C, Huang AS-E, et al. Diabetes and risk of tuberculosis relapse: nationwide nested case-control study. PLoS One 2014;9:e92623.

124 Mukhtar F, Butt ZA. Risk of adverse treatment outcomes among new pulmonary TB patients co-infected with diabetes in Pakistan: a prospective cohort study. PLoS One 2018;13:e0207148.

125 Castellanos-Joya M, Delgado-Sánchez G, Ferreyra-Reyes L, et al. Results of the implementation of a pilot model for the bidirectional screening and joint management of patients with pulmonary tuberculosis and diabetes mellitus in Mexico. PLoS One 2014;9:e106961.

126 Dávila Y, Castellanos M, García M. Advancement of the National strategy for integrated care in tuberculosis and diabetes mellitus in Mexico, 2015/Avance de la estrategia nacional para La atención integrada de la tuberculosis Y La diabetes mellitus en México, 2015. Int J Integr Care 2015;15.

127 Kapur A, Harries AD. The double burden of diabetes and tuberculosis-public health implications 2013;101:10-19.

128 Gounder S. Screening tuberculosis patients for diabetes mellitus in Fiji: notes from the field 2012;2:145-7.

129 Moher D, Liberati A, Tetzlaff J, et al. Preferred reporting items for systematic reviews and meta-analyses: the PRISMA statement. PLoS Med 2009;6:e1000097. 